\title{
Lifetime Occupational History, Respiratory Symptoms and Chronic Obstructive Pulmonary Disease: Results from a Population-Based Study
}

This article was published in the following Dove Press journal: International Journal of Chronic Obstructive Pulmonary Disease

\section{Denis Vinnikov (D) ${ }^{1-3}$ \\ Aizhan Raushanova' \\ Aizhan Kyzayeva $\mathbb{1 D}^{4}$ \\ Zhanna Romanova' \\ Zhangir Tulekov' \\ Dinara Kenessary ${ }^{5}$ \\ Ardak Auyezova ${ }^{6}$}

'Department of Epidemiology, Biostatistics and Evidence-Based Medicine, al-Farabi Kazakh National University, Almaty, Kazakhstan;

${ }^{2}$ Biological Institute, National Research Tomsk State University, Tomsk, Russian Federation; ${ }^{3}$ Department of Biochemistry, Peoples' Friendship University of Russia (RUDN University), Moscow, Russian Federation;

${ }^{4}$ Department of Biostatistics, Asfendiyarov Kazakh National Medical University, Almaty, Kazakhstan;

${ }^{5}$ Department of General Hygiene and Ecology, Asfendiyarov Kazakh National Medical University, Almaty, Kazakhstan; ${ }^{6}$ Department of Healthcare Management, KSPH Kazakhstan Medical University, Almaty, Kazakhstan
Correspondence: Denis Vinnikov Department of Epidemiology, Biostatistics and Evidence-Based Medicine, Al-Farabi Kazakh National University, Al-Farabi Avenue 7I, Almaty 050040, Kazakhstan Tel +7 7273773333

Fax +7 7273773344

Email denisvinnikov@mail.ru
Purpose: To ascertain the effect of lifelong occupational history, ambient air pollution, and biochemically verified smoking status on chronic obstructive pulmonary disease (COPD) in a general population of one the largest cities in Central Asia, Almaty.

Patients and methods: 1500 adults (median age 49, interquartile range (IQR) 28 years), $50 \%$ females, were randomly selected from a registry of enlisted population of a primary care facility in Almaty, Kazakhstan and they filled in the questionnaire on demographics, respiratory symptoms (CAT and mMRC), smoking status, verified by exhaled carbon monoxide, and detailed lifetime occupational history. COPD was defined as postbronchodilator forced expiratory volume in 1 second (FEV1)/forced vital capacity (FVC) below lower limit of normal (LLN) using Belintelmed MAS-2 spirometer (Belarus).

Results: $230(15 \%)$ subjects had $\mathrm{CAT} \geq 10 ; 136$ (9\%) participants had mMRC score $\geq 2$. Greater CAT score was associated with age, smaller income, and less exercise, but not with smoking or living closer to a major road. $26 \%$ of the population was ever exposed to vapors, gases, dusts, and fumes (VGDF). In age group 40 years and above ( $\mathrm{N}=1024)$, COPD was found in 57 participants (prevalence $5.6 \%$ ), more in men $(8.7 \%$ vs $3.4 \%)$. In the multivariate model adjusted for age, sex, ever-smoking, income, and exercise, any exposure to VGDF increased the odds of COPD (odds ratio (OR) 1.71; 95\% confidence interval (CI) $1.03 ; 2.84$ ), more in the highest exposure category (OR 2.36 (95\% CI 1.20; 4.66)).

Conclusion: Lifetime exposure to VGDF, found in $1 / 4$ of the general population, increased the odds of COPD independent of smoking by $71 \%$.

Keywords: occupational, regression, smoking, COPD

\section{Introduction}

Chronic obstructive pulmonary disease (COPD) is a progressing condition with accelerated lung function decline, which requires early recognition and treatment and is often associated with smoking, ${ }^{1,2}$ air pollution, ${ }^{3,4}$ and occupational exposure to noxious gases and particles in the workplace. ${ }^{5} \mathrm{~A}$ recent comprehensive review on the occupational burden of respiratory disease concluded that every tenth COPD case may be attributed to hazardous occupations. ${ }^{5}$ Occupational surveillance programs are therefore essential to detect accelerated lung function decline in those at risk, to offer smoking cessation and increase workers' awareness of the inhaled hazards.

Most, if not all, epidemiological evidence on the occupational burden of COPD has emerged from the West, ${ }^{5}$ whereas the industry transition to the East in recent 
decades will imply the greatest burden in the developing nations, where most current and future patients reside. The lack of high-quality studies in developing nations coupled with high smoking prevalence and poor workplace surveillance programs may leave most patients unattended, when some action can still be taken to prevent the disease or slow its progression. Thus, there exists only one epidemiological study on COPD from the region of Central Asia, ${ }^{6}$ showing 2 -fold greater likelihood of COPD in those exposed to dust in the workplace, but no detailed stratification of occupations analyzed is provided. Moreover, with the evolving chemical technology in recent decades, novel exposures need more attention, and a lifelong occupational history would help to better understand the true association of such hazards with COPD.

There is always a complex interplay of smoking with occupational hazards in the cohort of middle-aged healthy workers, ${ }^{7}$ because smoking prevalence is usually high in the exposed population. Better methodology is needed to clearly distinguish between the effects of smoking and occupational exposures. Finally, ambient air pollution is often not regarded as an important confounder in the occupational studies, despite growing evidence that it is independently associated with greater risk of COPD ${ }^{8-10}$ Therefore, the aim of the current analysis was to ascertain the effect of lifelong occupational history, ambient air pollution, and biochemically verified smoking status with COPD in general population of one the largest cities in Central Asia, Almaty.

\section{Materials and Methods}

This population-based study was approved by the Committee on Bioethics of the Faculty of Medicine and Healthcare of al-Farabi Kazakh National University and was conducted in accordance with the Declaration of Helsinki. Each participant provided written and signed informed consent prior to inclusion. Sample size for this study was calculated with the assumption that COPD is usually diagnosed in people older than 40 , and, therefore, we considered two subgroups in this analysis for sample calculation, including those below 40 and those older than 40. Given that the estimated prevalence of this disease in the population is $10 \%$ and the margin error set to $3 \%, 95 \%$ will be achieved with a sample of 470 subjects in each subgroup; thus, making the overall sample of 940 subjects. In addition, we considered that a fraction of our sample would have missing data or poor-quality spirometry; therefore, we increased sample size by $1 / 3$, and the final sample size in our protocol was 1500 subjects. We recruited subjects from the general population using random numbers in the list of all signed population of one of the primary care facilities in Almaty. The facility covers a population of $85,000+$ residents, including $66,000+$ adults (aged 18 or older). We only selected adult population, and then a nurse invited those selected to attend the clinic by phone in the morning of any day. Participants' recruitment was completed in March through July 2019. All visits took place in a specially designated room of the primary care facility.

\section{Questionnaire}

We created our own questionnaire for this study, using parts of alternative questionnaires validated in other studies. Demographic section included questions on date of birth, sex, mobile phone, and exact permanent address and the overall work duration in all positions. Socioeconomic determinants were defined via the highest attained education and the total household income per month stratified into three options: 1) 100,000 tenge a month or less; 2) 101,000 to 500,000 tenge a month, and 3) 501,000 tenge or more a month. Self-reported cigarette smoking status was verified with 5 consecutive questions, which enabled us to assign a subject to one of four categories: 1) neversmoker; 2) ex-smoker; 3) current occasional smoker, and 4) current daily smoker. We also asked about the mean number of smoked cigarettes per day and smoking duration in years. Two questions covered waterpipe smoking and one more question was on electronic cigarette use. We then combined two questions from FreshAir study on the use of fossil fuel for heating and cooking with the question on secondhand smoke exposure in the workplace, public place or at home. The first section of the questionnaire ended with the question on regular exercise at least 3 times a week and one more question on alcohol use, where 4 options of answers were offered, including "never", "less than once a week", "at least once a week", and "moderate amounts a few times a week".

The second section included COPD Assessment Test (CAT), validated Russian version, as it appears in Kazakhstan clinical protocol on COPD. This is an 8-item test with answer options from 0 to 5 each, which allows distinction between patients with "more symptoms" from "fewer symptoms". We also offered mMRC, a 1-item test with the total score ranging from 0 to 4 . The following questions asked whether the subject had ever had 1) asthma; 2) chronic bronchitis; 3) COPD, and 4) allergic rhinitis, diagnosed by a physician. 


\section{Lifetime Occupational History}

From each subject, we collected information on all positions he or she ever had in life with the corresponding work duration of each. Similar occupations, like manager, director or administrator were treated as one category. Based on our expert concilium, we then selected occupations, which could have exposure to vapors, gases, dusts or fumes (VGDF) and coded them as those with such exposure. These occupations included any jobs in construction, non-construction laborer, foreman in industry, industrial mechanic, machinist, metalworker, welder, industrial technologist, hairdresser, industrial installer, machine operator, carpenter, fuel station operator, coddler, baker, miner and metallurgist. We summed the employment duration in each of these positions in one worker, since they may have been employed in various positions in his/her lifetime.

\section{Proximity to a Major Road}

Because we collected exact permanent residence address of each participant, we analyzed their proximity to a major city road as a surrogate of air pollution from the traffic. We checked exact location of every house on the detailed geographical map using online resource www.yandex.kz. Apartment blocks or houses were categorized into those located in the first, second, third, fourth and fifth rows from a major road.

\section{Spirometry}

Each subject was invited to undergo spirometry right after the questionnaire was completed if he/she refrained from smoking for at least $2 \mathrm{hrs}$ prior to the procedure. No national guidelines on spirometry have ever been published in Kazakhstan. We, therefore, were guided by the national guidelines from Kyrgyzstan ${ }^{11}$ and ERS guidelines ${ }^{12}$ in terms of quality control. We obtained three vital capacity (VC) maneuvers with a reproducibility of $4 \%$ or less (or $150 \mathrm{~mL}$ max) and three forced VC (FVC) maneuvers with the same reproducibility. Each expiration lasted for at least 6 seconds, no end-of-test errors, no slow start, no expiration interruption and maximum peak expiratory flow in the very onset of the expiration were required for each maneuver. In the current analysis, we analyzed forced expiratory volume in one second (FEV1) and FVC actual values and their corresponding percent of predicted, for which we used ECCS predicted values. For bronchodilation test, we used $300 \mathrm{mcg}$ of salbutamol, and the test was considered positive should FEV1 change by $12 \%$ or more and $200 \mathrm{~mL} 15$ mins after salbutamol inhalation. All tests were performed using calibrated desktop spirometer MAS-2 (Belintelmed LLN, Belarus).

\section{Exhaled Carbon Monoxide Measurement}

Exhaled carbon monoxide (CO) was the biochemical daily smoking verification method. Readings 7 parts per million (PPM) and above confirmed daily smoking. Values below $7 \mathrm{ppm}$ could be found in any smoking status, including daily smoking. Self-reported non-smoking (never or exsmoking) status with exhaled $7 \mathrm{ppm}$ and above was considered daily smoking. Therefore, exhaled $\mathrm{CO}$ measurement confirmed daily smokers only, but the measurement was done in all subjects. All measurements were done once after 15 seconds of deep inspiration using piCO Smokerlizer (Bedfont, UK).

\section{COPD Diagnosis}

COPD was defined as irreversible bronchial obstruction in a subject 40 years or older irrespective of risk factors or symptoms at a time of examination. Such obstruction was present if postbronchodilator FEV1/FVC was below lower limit of normal (LLN). Patients with FEV1/FVC below LLN, but with positive bronchodilation test were not considered COPD patients as they needed further examination to exclude asthma. LLN was computed as (predicted value $-1.64 *$ standard deviation (SD)), where predicted values for FEV1/FVC for each patient were calculated using ECCS equations. The equation for FEV1/FVC predicted value takes sex and age into account only.

\section{Statistical Analysis}

The primary outcome of interest was COPD as a binary variable in the entire sample. However, we also analyzed $\mathrm{CAT} \geq 10$ and $\mathrm{mMRC} \geq 2$ as binary variables in the univariate analyses. Since most distributions, including age, were non-normal, we only utilized nonparametric techniques, including Mann-Whitney $U$-test for continuous variables and $\chi^{2}$ test for binary variables in the univariate comparisons. A number of predictors were selected and tested in the univariate comparisons, where respiratory symptoms, such as $C A T \geq 10$ and $m M R C \geq 2$ and then, additionally, COPD (yes/no) were the outcomes of interest. Significant predictors with $\mathrm{p}<0.05$ were further included in a multivariate model to test whether they were independent of the covariates in their association with COPD. For such multivariate model, we used logistic regression, where COPD (yes/no) was a dependent variable. The latter 
logistic regression was further extended to test whether cumulative years of exposure in all VGDF jobs could predict COPD. For this, VGDF exposure as a variable was coded to (0) referents, those with no VGDF exposure at all; (1) 0-9 years of exposure; (2) 10-22 years of exposure; and finally (3) 23 or more years of exposure, guided by the distribution. Logistic regression results are presented as odds ratios (ORs) with their corresponding 95\% confidence intervals (CIs). Population attributable fraction $\%(\mathrm{PAF} \%$ ) was computed using the formula PAF $\%=p^{*}(\mathrm{OR}-1) /\left(\mathrm{p}^{*}(\mathrm{OR}-1)+1\right)$, where $\mathrm{p}$ was proportion of exposed population. All tests were completed in NCSS 13 (Utah, USA).

\section{Results}

Questionnaires with no missing data, spirometry of acceptable quality and exhaled $\mathrm{CO}$ data were obtained from 1500 patients, 748 (50\%) of whom were men. Age ranged from 18 to 91 years with the median 49 (interquartile range (IQR) 28) years, and females in the study were older than males. Half of the sample had any university degree, but only $2 \%$ had a household income exceeding 501,000 tenge (1290 USD) a month. Women were generally more educated, but had smaller income compared to men. Significant differences were also noted between female and male populations with regard to waterpipe smoking, electronic cigarette use, exposure to SHS, alcohol and the use of fossil fuel for heating and cooking (Table 1). 525 (35\%) stated they ever had a diagnosis of chronic bronchitis; 77 (5\%) said they ever had COPD; 89 (6\%) ever had physician-diagnosed asthma; and 267 $(18 \%)$ ever had a diagnosis of allergic rhinitis.

Six-hundred and twenty (41\%) subjects never smoked cigarettes. The remaining 880 ever-smokers included 418 (28\%) ex-smokers and 462 (31\%) current smokers. 394 (26\%) responders smoked cigarettes daily, leaving 67 (5\%) occasional smokers. In those who smoked cigarettes at least once a day, the median number of cigarettes per day was 10 (IQR 15), whereas the smoking duration was 18 (IQR 22) years. There were significantly more never-smokers in females ( $62 \%$ vs $20 \%$ ); fewer exsmokers $(20 \%$ vs $36 \%)$; fewer current smokers $(18 \%$ vs $44 \%$ ), whereas the count of occasional smokers did not differ with regard to sex.

Most included subjects were employed as managers and directors, in sales and in accounting and as economists (Table 2). One-third of the sample $(\mathrm{N}=508)$ was employed in one or more of these three occupations in their lifetime.
Table I Age, Employment History, Socioeconomic and Smoking Status Along with Alcohol Use of the Study Participants

\begin{tabular}{|c|c|c|c|c|}
\hline Indicator & Total & Men & Women & $\mathbf{p}$ \\
\hline N (\%) & 1500 & $748(50)$ & $752(50)$ & \\
\hline Age, years & $49(28)$ & $45(29)$ & $54(23)$ & 0.001 \\
\hline $\begin{array}{l}\text { Total employment } \\
\text { history, years }\end{array}$ & $25(24)$ & $22(25)$ & $25(20)$ & 0.01 \\
\hline $\begin{array}{l}\text { Highest attained } \\
\text { education, N (\%) } \\
\text { Secondary school } \\
\text { High school } \\
\text { College } \\
\text { University } \\
\text { Academic degree }\end{array}$ & $\begin{array}{l}15(1) \\
282(19) \\
416(28) \\
764(51) \\
23(1)\end{array}$ & $\begin{array}{l}8(1) \\
179(24) \\
173(23) \\
373(50) \\
15(2)\end{array}$ & $\begin{array}{l}7(1) \\
103(14) \\
243(32) \\
391(52) \\
8(1)\end{array}$ & 0.001 \\
\hline $\begin{array}{l}\text { Monthly household } \\
\text { income, tenge } \\
100,000 \text { or less } \\
101,000 \text { to } 500,000 \\
\text { tenge } \\
501,000 \text { or more }\end{array}$ & $\begin{array}{l}535(36) \\
925(62) \\
36(2)\end{array}$ & $\begin{array}{l}242(32) \\
485(65) \\
20(3)\end{array}$ & $\begin{array}{l}293(39) \\
440(59) \\
16(2)\end{array}$ & 0.02 \\
\hline $\begin{array}{l}\text { Proximity to a major } \\
\text { road at a place of } \\
\text { residence } \\
\text { Ist row } \\
2 \text { nd row } \\
3 \text { rd row } \\
4 \text { th row } \\
\text { 5th row }\end{array}$ & $\begin{array}{l}519(35) \\
564(38) \\
270(18) \\
122(8) \\
24(1)\end{array}$ & $\begin{array}{l}260(35) \\
277(37) \\
136(18) \\
62(8) \\
12(2)\end{array}$ & $\begin{array}{l}259(34) \\
287(38) \\
134(18) \\
60(8) \\
12(2)\end{array}$ & 0.99 \\
\hline $\begin{array}{l}\text { Waterpipe smoking, } \\
N(\%)\end{array}$ & $143(10)$ & $109(15)$ & $34(5)$ & 0.001 \\
\hline $\begin{array}{l}\text { Electronic cigarette use, } \\
N(\%)\end{array}$ & $45(3)$ & $34(5)$ & II (I) & 0.001 \\
\hline Exposure to SHS, N (\%) & $610(4 I)$ & $331(44)$ & $279(37)$ & 0.01 \\
\hline $\begin{array}{l}\text { Use of fossil fuel for } \\
\text { heating, } N(\%)\end{array}$ & $45(3)$ & $15(2)$ & $30(4)$ & 0.02 \\
\hline $\begin{array}{l}\text { Use of fossil fuel for } \\
\text { cooking, } N(\%)\end{array}$ & $13(1)$ & $4(1)$ & $9(1)$ & 0.03 \\
\hline $\begin{array}{l}\text { Exercise } 3 \text { times a week } \\
\text { or more, } N(\%)\end{array}$ & $462(3 I)$ & $248(33)$ & $214(28)$ & 0.05 \\
\hline $\begin{array}{l}\text { "Never" alcohol use, } \\
\mathrm{N}(\%)\end{array}$ & $746(50)$ & $310(4 I)$ & $436(58)$ & 0.001 \\
\hline
\end{tabular}

Notes: SHS, secondhand smoke; pairwise comparisons are from $\chi^{2}$ test or MannWhitney U-test (age). Tests of education, household income and proximity to a major road are from $2 * 5$ and $2 * 3$ tests.

Table 2 shows that a large fraction of included population worked in schools and academia, as engineers and in construction. Of 54 included occupations, 15 were 
Table 2 Lifetime Occupational History of the Included Population

\begin{tabular}{|c|c|c|c|}
\hline Occupation & N (\%) & $\begin{array}{l}\text { Employment } \\
\text { Years Range } \\
\text { (Median) }\end{array}$ & $\begin{array}{l}\text { Included } \\
\text { in VGDF }\end{array}$ \\
\hline $\begin{array}{l}\text { Manager, director, } \\
\text { human resources staff }\end{array}$ & $222(15)$ & $0.5-50(10)$ & No \\
\hline Sales & $143(10)$ & $0.5-25(10)$ & No \\
\hline $\begin{array}{l}\text { Economist, accountant, } \\
\text { cashier }\end{array}$ & $143(10)$ & $\mathrm{I}-50(16)$ & No \\
\hline $\begin{array}{l}\text { School teacher, } \\
\text { university faculty, } \\
\text { scientific work }\end{array}$ & $137(9)$ & $\mathrm{I}-58(20)$ & No \\
\hline $\begin{array}{l}\text { Laborer, non- } \\
\text { construction }\end{array}$ & 118 (9) & $\mathrm{I}-43(10)$ & Yes \\
\hline $\begin{array}{l}\text { Non-construction } \\
\text { engineer }\end{array}$ & III (7) & $\mathrm{I}-50(\mathrm{II})$ & No \\
\hline Driver & $104(7)$ & $\mathrm{I}-50(\mathrm{I})$ & No \\
\hline $\begin{array}{l}\text { Governmental } \\
\text { employee, office } \\
\text { unspecified }\end{array}$ & $101(7)$ & $\mathrm{I}-40(12)$ & No \\
\hline Construction & $96(6)$ & $1-46(10)$ & Yes \\
\hline Nurse, paramedic & $82(6)$ & $0.5-56(15)$ & No \\
\hline Business, unspecified & $78(5)$ & $1-37(10.5)$ & No \\
\hline $\begin{array}{l}\text { Cook, waiter, barman, } \\
\text { public catering staff }\end{array}$ & $76(5)$ & $0.5-50(7.5)$ & No \\
\hline Security guard & $58(4)$ & $1-30(8)$ & No \\
\hline Foreman, industrial & $56(4)$ & $\mathrm{I}-45(\mathrm{I} 8.5)$ & Yes \\
\hline $\begin{array}{l}\text { Kindergarten teacher, } \\
\text { babysitter }\end{array}$ & $54(4)$ & $1-36(10)$ & No \\
\hline $\begin{array}{l}\text { Medical or veterinary } \\
\text { doctor, biologist }\end{array}$ & $41(3)$ & $\mathrm{I}-63(15)$ & No \\
\hline Military, fireman & $36(2)$ & $2-50(13.5)$ & No \\
\hline Sewer worker & $33(2)$ & $2-4 \mid(\mid 4)$ & No \\
\hline Industrial mechanic & $31(2)$ & $\mathrm{I}-45(15)$ & Yes \\
\hline Police & $29(2)$ & $\mathrm{I}-47(20)$ & No \\
\hline Electrician & $27(2)$ & $\mathrm{I}-50(13)$ & No \\
\hline $\begin{array}{l}\text { Machinist, vehicle } \\
\text { operator }\end{array}$ & $26(2)$ & $1-47(12)$ & Yes \\
\hline Metalworker & $26(2)$ & $\mathrm{I}-42(7.5)$ & Yes \\
\hline $\begin{array}{l}\text { Secretary, dispatcher, } \\
\text { call operator }\end{array}$ & $26(2)$ & $1-32(4.5)$ & No \\
\hline Agricultural worker & $24(2)$ & $2-28(14.5)$ & No \\
\hline Welder & $24(2)$ & $0.5-49(13)$ & Yes \\
\hline Programmer & $22(I)$ & $\mathrm{I}-30(5)$ & No \\
\hline Technologist, industrial & $22(2)$ & $2-40(19)$ & Yes \\
\hline Lab technician & $20(1)$ & $\mathrm{I}-38(12)$ & No \\
\hline $\begin{array}{l}\text { Artist, designer, } \\
\text { photographer, draftsman }\end{array}$ & $17(1)$ & $1-40(13)$ & No \\
\hline Lawyer & $17(1)$ & $2-34(10)$ & No \\
\hline Hairdresser & $16(1)$ & $\mathrm{I}-25(\mathrm{I0})$ & Yes \\
\hline Industrial installer & $16(1)$ & $2-40(10)$ & Yes \\
\hline Sports instructor & $15(I)$ & $\mathrm{I}-30(8)$ & No \\
\hline Controller, inspector & $14(1)$ & $\mathrm{I}-34(7.5)$ & No \\
\hline
\end{tabular}

(Continued)
Table 2 (Continued).

\begin{tabular}{|l|l|l|l|}
\hline Occupation & N (\%) & $\begin{array}{l}\text { Employment } \\
\text { Years Range } \\
\text { (Median) }\end{array}$ & $\begin{array}{l}\text { Included } \\
\text { in VGDF }\end{array}$ \\
\hline Plumber & $13(1)$ & $1-48(14)$ & No \\
Geologist, geophysicist & $13(1)$ & $7-35(18)$ & No \\
Machine operator & $12(1)$ & $1-35(7.5)$ & Yes \\
Pharmacist & $10(1)$ & $2-30(15.5)$ & No \\
Actor in theater, ballet & $10(1)$ & $4-48(17)$ & No \\
or opera & & & \\
Logistics & $9(1)$ & $1-15(6)$ & No \\
Printer & $8(1)$ & $1-40(5.5)$ & No \\
Carpenter & $8(1)$ & $1-28(9)$ & Yes \\
Musician & $7(1)$ & $20-47(3)$ & No \\
Fuel station operator & $6(1)$ & $1-11(2)$ & Yes \\
Architect & $6(1)$ & $3-40(20.5)$ & No \\
Librarian & $6(1)$ & $1-43(21.5)$ & No \\
Coddler & $4(1)$ & $3-52(15)$ & Yes \\
Baker & $4(1)$ & $1-10(4.5)$ & Yes \\
Translator & $3(1)$ & $2-15(15)$ & No \\
Gardener & $3(1)$ & $3-14(3)$ & No \\
Pilot, air crew & $2(1)$ & $8-37(22.5)$ & No \\
Journalist & $2(1)$ & $13-28(20.5)$ & No \\
Psychologist & $2(1)$ & $8-28(18)$ & No \\
Metallurgist & $1(1)$ & 22 & Yes \\
Miner & $1(1)$ & 4 & Yes \\
Train conductor & $1(1)$ & 17 & No \\
\hline
\end{tabular}

Abbreviation: VGDF, vapors, gases, dusts and fumes.

considered to have some VGDF exposure, and such patients were treated as exposed population in the subsequent analyses. In the entire sample, 386 subjects had any occupation with VGDF exposure, therefore, $26 \%$ of the population was exposed, and the overall number of VGDF occupations was 17.

Two-hundred and thirty (15\%) subjects had high CAT score indicative of persistent respiratory symptoms. The strongest predictor of more symptoms (CAT $\geq 10)$ was COPD. We found significantly more COPD patients in more symptoms group as compared to the groups with less symptoms $(12 \%$ vs $4 \%$ patients, $\mathrm{p}<0.001)$. Living closer to a major road, a surrogate for greater exposure to air pollution, as well as education, smoking, exposure to SHS failed to predict more symptoms in our population (Table 3), however regular exercise was protective against worse symptoms. 136 (9\%) participants had high mMRC score, consistent with worse respiratory condition. Both CAT and mMRC were consistent in predicting worse respiratory symptoms in those with lower monthly 
household income. As opposed to CAT, worse dyspnea was associated with exposure to SHS and poorer education. Similar to CAT, we found no association of living closer to a major road with more advanced dyspnea measured with mMRC.

Postbronchodilator $\mathrm{FEV}_{1} / \mathrm{FVC}$ below LLN was found in 72 subjects, resulting in the overall COPD prevalence of $4.8 \%$, more in males $(6.4 \%)$ compared to females $(3.2 \%)$. Of these 72 confirmed COPD cases, only 17 (24\%) had a diagnosis of COPD before. Also, of 77 patients with a physician's diagnosis of COPD before, we could confirm the diagnosis with spirometry in 17 only (22\%). In age group 40 years and above $(\mathrm{N}=1024)$, spirometrically verified COPD was found in 57 participants (prevalence $5.6 \%)$, also more in men $(8.7 \%$ vs $3.4 \%)$. In the univariate comparisons, COPD was associated with advanced age, worse education, smaller household income, smoking, less exercise, and any VGDF exposure, but not with living close to a major road, exposure to SHS or alcohol (Table 4). Age, sex, smoking, and occupational exposure had the greatest power in predicting COPD in such comparisons. Ever-smoking was more prevalent in the exposed population than in those non-exposed (68\% vs 55\%), therefore, there may be a complex interaction between smoking and occupational exposures in COPD causation. In order to separate the effect of smoking from any VGDF exposure in the workplace, we included age, sex, smoking, any VGDF employment, exercise, and income in a multivariate logistic regression model, where COPD (yes/no) was a dependent variable.

In the multivariate model adjusted for these significant predictors, any exposure to VGDF almost doubled the odds of COPD (OR 1.71; 95\% CI 1.03;2.84). Of note, household income was no more significant in this
Table 4 Predictors of COPD

\begin{tabular}{|l|l|l|l|}
\hline Predictor & COPD & $\begin{array}{l}\text { No } \\
\text { COPD }\end{array}$ & P \\
\hline Age above median, N (\%) & $49(68)$ & $696(49)$ & 0.01 \\
Female sex, N (\%) & $24(33)$ & $728(5 \mathrm{I})$ & 0.0 I \\
Monthly household income above & $37(5 \mathrm{I})$ & $924(65)$ & 0.02 \\
I0I,000 tenge, N (\%) & & & \\
Living in the Ist row of houses from & $26(36)$ & $493(33)$ & 0.78 \\
the road, N (\%) & & & \\
Ever smokers, N (\%) & $53(74)$ & $826(58)$ & 0.01 \\
Exposure to SHS, N (\%) & $31(43)$ & $579(4 \mathrm{I})$ & 0.67 \\
Exercise 3 times a week or more, & $14(19)$ & $448(3 \mathrm{I})$ & 0.03 \\
N (\%) & & & \\
"Never" alcohol use, N (\%) & $34(47)$ & $712(50)$ & 0.66 \\
Any VGDF employment, N (\%) & $33(46)$ & $353(25)$ & $0.00 \mathrm{I}$ \\
\hline
\end{tabular}

Abbreviations: VGDF, vapors, gases, dusts and fumes; SHS, secondhand smoke; COPD, chronic obstructive pulmonary disease.

multivariate model (Table 5). Our multivariate logistic regression was further extended in order to account for the cumulative years of exposure to VGDF, where the lowest exposure category was below 10 years; the intermediate category was 10 to 23 years, and finally the highest exposure category was 23 years and above. Figure 1 shows that the highest exposure category in terms of work duration in any VGDF occupation was significantly associated with COPD (OR 2.36 (95\% CI 1.20;4.66)). Finally, PAF\% associated with VGDF equaled $15.6 \%$ in our population, given that $26 \%$ of the population was exposed and the OR of COPD was 1.71 .

\section{Discussion}

This is the first presentation of a population-based study of lifetime occupational risks of COPD in a general population from Kazakhstan, in which we showed that after adjustment for smoking, age, socioeconomic status, and

Table 3 Respiratory Symptoms and Their Predictors in Study Participants

\begin{tabular}{|c|c|c|c|c|c|c|}
\hline Predictor & CAT $<10$ & CAT $\geq 10$ & $\mathbf{p}$ & $\mathrm{mMRC}<2$ & mMRC $\geq 2$ & $\mathbf{p}$ \\
\hline Age above median, $\mathrm{N}(\%)$ & $574(45)$ & $169(74)$ & 0.001 & $629(46)$ & II 4 (84) & 0.001 \\
\hline Female sex, $\mathrm{N}(\%)$ & $608(48)$ & $144(63)$ & 0.001 & $672(49)$ & $80(59)$ & 0.03 \\
\hline Education college, university academic degree, N (\%) & $1023(8 \mathrm{I})$ & $180(78)$ & 0.42 & II $02(8 \mathrm{I})$ & $99(73)$ & 0.04 \\
\hline Monthly household income above $10 \mathrm{I}, 000$ tenge, $\mathrm{N}(\%)$ & $848(67)$ & $117(5 \mathrm{I})$ & 0.001 & $888(65)$ & $71(53)$ & 0.01 \\
\hline Living in the Ist row of houses from the road, $\mathrm{N}(\%)$ & $429(34)$ & $88(38)$ & 0.18 & $466(34)$ & $52(39)$ & 0.31 \\
\hline Daily smokers, N (\%) & $334(26)$ & $60(26)$ & 0.94 & $372(28)$ & $22(17)$ & 0.01 \\
\hline Exposure to SHS, N (\%) & $529(42)$ & $81(35)$ & 0.07 & $575(42)$ & $33(24)$ & 0.001 \\
\hline Exercise 3 times a week or more, $\mathrm{N}(\%)$ & $417(33)$ & $45(20)$ & 0.001 & $440(32)$ & $20(15)$ & 0.001 \\
\hline “Never” alcohol use, N (\%) & $616(49)$ & $130(57)$ & 0.16 & $660(48)$ & $84(62)$ & 0.01 \\
\hline Any VGDF employment, $\mathrm{N}(\%)$ & $305(24)$ & $81(35)$ & 0.06 & $326(24)$ & $60(44)$ & 0.001 \\
\hline
\end{tabular}

Abbreviations: VGDF, vapors, gases, dusts and fumes; SHS, secondhand smoke. 
Table 5 Logistic Regression of COPD (Yes/No) Adjusted for All Included Variables

\begin{tabular}{|l|l|l|}
\hline Predictor & OR & $\mathbf{9 5 \% ~ C l ~}$ \\
\hline Age & 1.03 & $1.01 ; 1.04$ \\
Female sex & 0.53 & $0.30 ; 0.95$ \\
Monthly household income above I0I,000 tenge & 0.67 & $0.41 ; 1.11$ \\
Ever smoking & 1.65 & $1.30 ; 3.03$ \\
Exercising 3 times a week or more & 0.54 & $0.29 ; 0.98$ \\
Any VGDF employment & 1.71 & $1.03 ; 2.84$ \\
\hline
\end{tabular}

Abbreviations: VGDF, vapors, gases, dusts and fumes; SHS, secondhand smoke; COPD, chronic obstructive pulmonary disease; OR, odds ratio; $\mathrm{Cl}$, confidence interval.

regular exercise, any VGDF exposure almost doubled the risk of COPD, and the risk further increased in the highest exposure category. We also found that clinically significant respiratory symptoms are present in $9-15 \%$ of the population, whereas proximity to a major road in the city as a surrogate of greater air pollution from traffic was not associated with respiratory symptoms or COPD.

COPD prevalence in our analysis in the age group 40 and older equaled $5.6 \%$, more in men ( $8.7 \%$ vs $3.4 \%)$, which was obviously different compared to another population-based study in Kazakhstan. ${ }^{6}$ As opposed to the first study, which was guided by postbronchodilator $\mathrm{FEV} 1 / \mathrm{FVC}<0.70$, we only considered COPD in those with postbronchodilator FEV1/ FVC $<$ LLN. Despite very wide use of FEV1/FVC $<0.70$ as COPD criterion, also recommended by GOLD,${ }^{13}$ fixed ratio is known to overestimate $\mathrm{COPD},{ }^{14-16}$ especially in the elderly, ${ }^{16}$ as it does not account for age-related natural FEV1/FVC drop, and false-positive COPD is frequent. ${ }^{17}$

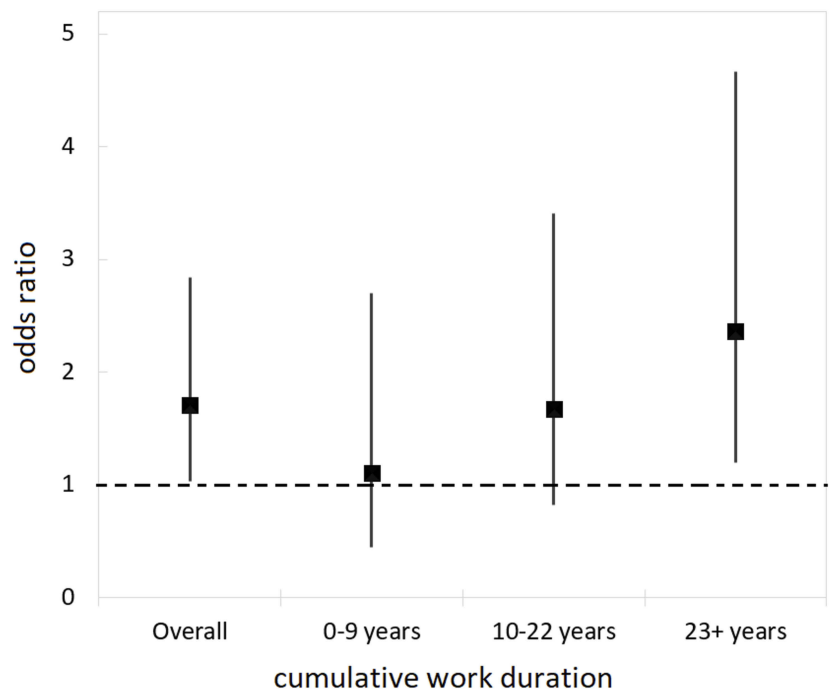

Figure I The odds ratios of COPD in different cumulative exposure categories from a multivariate logistic regression model.
Therefore, the use of LLN is believed to give a better representation of COPD with advanced age, although it is not advantageous in predicting all-cause of COPD-specific mortality. ${ }^{18}$ Furthermore, when COPD is considered in those with symptoms on top of spirometric criteria, the prevalence is expected to be even smaller. ${ }^{14}$ The overall COPD prevalence in our presentation is consistent with other studies elsewhere, where LLN was used for COPD diagnosis. ${ }^{14,19}$

Despite its better accuracy, LLN approach is limited to the use of predicted values. In Kazakh population, predicted values have never been published, whereas widely used Global Lung Function Initiative (GLI) 2012 reference equations using spline method did not include any population from Central Asia, and, therefore, have never been tested in this population. Hence, conclusions on COPD prevalence based on LLN should be interpreted with some criticism, since additional studies and further research are needed to assess the applicability of European reference values to a Kazakh population. To date, there is no evidence on how prominent the discrepancy, if any, between European and Kazakh predicted values can be.

Defining occupational history is not simple, and despite wide use of job-exposure matrixes (JEMs), exposure classification in a single worker is still challenging. Self-reported occupational history may be prone to classification bias, whereas JEM may not provide sufficient accuracy, and expert classification of jobs into those with or without exposure may also be subjective. Lifetime occupational history analysis is popular, ${ }^{20}$ as it gives a broader perspective of any job held with VGDF, considering both the intensity and prevalence of exposure. Consistent with other similar reports, ${ }^{20,21}$ we found a 2 -fold increase of COPD likelihood in those exposed, when COPD is defined spirometrically. Of note, a meta-analysis of a number of studies found that the pooled OR for any VGDF exposure was 1.43 (95\% CI $1.19-1.73){ }^{22}$ When a lifetime occupational history is collected with further expert evaluation as to whether VGDF exposure was present, this provides a more accurate estimate of the effect as compared to selfreported exposure to VGDF. In this regard, our findings are more consistent with studies in other countries than another Kazakhstan study using self-reported estimates (OR 2.3). ${ }^{6}$ Interestingly, almost similar magnitude of effect was found in specific populations, like miners, when highly exposed workers are compared to those with low exposure, ${ }^{7}$ or tractor plant workers. ${ }^{23}$ In our multiple regression model, the strength of effect associated with occupational exposure may be as high as the one of smoking, and this will dictate 
the need for exposure reduction programs as intense as smoking cessation programs, including the ones in the workplace.

We failed to explain any association of local differences in air pollution from the traffic with either symptoms or COPD, as both CAT, mMRT scores, and COPD prevalence were similar in those living in the first, second, third or even fifth row of houses from the major road. Outdoor air pollution in studies elsewhere consistently showed greater likelihood of respiratory symptoms in both children and adults ${ }^{24-27}$ and COPD. ${ }^{8-10}$ We hypothesize, that the basic air pollution level in Almaty is so high, that a distance of 50 to 100 meters from a major road cannot play a role in worsening the symptoms. Despite known very high levels of air pollution in Almaty, including particulate matter, especially in winter, no scientific analysis of air pollution levels has been published to date. Further research in this regard should concentrate on more accurate ways of measuring air pollution and their surrogates in order to quantify their effect on respiratory health in Almaty residents.

The strengths of this epidemiological study are the use of biochemical verification of smoking status, detailed occupational lifetime history, and COPD diagnosis based on LLN as opposed to fixed ratio. Limitations of this population-based study should also be noted. Firstly, as mentioned previously, no reference values, including FEV1/FVC for Kazakh population are available, which may limit the interpretation of COPD diagnoses based on that criterion as opposed to the use of fixed value. Secondly, our occupational analysis was confined by occupations of included subjects and may have omitted some other important, but less prevalent occupations, including the ones with exposure to VGDF. In another report, the authors found the strongest effect attributed to hairdressers, ${ }^{20}$ which we could not confirm in our study, because of a very small number of hairdressers in our population. Thirdly, we only assessed self-reported employment history with no access to population labor registry, because it does not exist in Kazakhstan, and no exposure assessment data with regard to particulate matter or gas concentrations in the workplaces were at our disposal.

Our results have distinct implications for occupational medicine. Contrary to the time when Kazakhstan was part of the Soviet Union with very developed industry, contemporary labor profile of population is noted for fewer people employed in jobs in the industry and thus exposed to VGDF. Most people are now employed as managers, administrators, economists, accountants and similar positions, reducing the role of industry in COPD in the population. Nevertheless, smoking prevalence remains quite high in males, whereas the public health concern is growing around worsening urban air pollution in large cities like Almaty. Therefore, COPD prevalence is very unlikely to be reduced in the next decade, and more efforts should be directed to reducing smoking prevalence, cleaner outdoor and indoor air, and less exposure to VGDF in the workplace.

\section{Conclusion}

This population-based study of lifetime occupational history and its association with respiratory symptoms and COPD confirmed that exposure to VGDF remains an important risk factor for COPD along with smoking, each doubling the risk of COPD. COPD prevalence in those 40 years and older based on FEV1/FVC below LLN in Almaty is $5.9 \%$, more in men than in women. At present, COPD prevention programs should be built around smoking prevention and cessation and reduction of exposure to VGDF in the workplace.

\section{Acknowledgment}

We would like to thank the staff of Almaty policlinic \#4 for their assistance in the study.

\section{Disclosure}

The authors report no conflicts of interest in this work.

\section{References}

1. Wang B, Xiao D, Wang C. Smoking and chronic obstructive pulmonary disease in Chinese population: a meta-analysis. Clin Respir J. 2015;9(2):165-175. doi:10.1111/crj.12118

2. Hooper R, Burney P, Vollmer WM, et al. Risk factors for COPD spirometrically defined from the lower limit of normal in the BOLD project. Eur Respir J. 2012;39(6):1343-1353. doi:10.1183/09031936. 00002711

3. Bloemsma LD, Hoek G, Smit LAM. Panel studies of air pollution in patients with COPD: systematic review and meta-analysis. Environ Res. 2016;151:458-468. doi:10.1016/j.envres.2016.08.018

4. Song Q, Christiani DC, Xiaorong W, Ren J. The global contribution of outdoor air pollution to the incidence, prevalence, mortality and hospital admission for chronic obstructive pulmonary disease: a systematic review and meta-analysis. Int $J$ Environ Res Public Health. 2014;11(11):11822-11832. doi:10.3390/ijerph111111822

5. Blanc PD, Annesi-Maesano I, Balmes JR, et al. The occupational burden of nonmalignant respiratory diseases. An official American Thoracic Society and European Respiratory Society Statement. Am J Respir Crit Care Med. 2019;199(11):1312-1334. doi:10.1164/ rccm.201904-0717ST

6. Nugmanova D, Feshchenko Y, Iashyna L, et al. The prevalence, burden and risk factors associated with chronic obstructive pulmonary disease in Commonwealth of Independent States (Ukraine, Kazakhstan and Azerbaijan): results of the CORE study. BMC Pulm Med. 2018;18 (1):26. doi:10.1186/s12890-018-0589-5 
7. Vinnikov D. Drillers and mill operators in an open-pit gold mine are at risk for impaired lung function. J Occup Med Toxicol. 2016;11 (1):27. doi:10.1186/s12995-016-0114-9

8. Kotaki K, Ikeda H, Fukuda T, et al. Trends in the prevalence of COPD in elderly individuals in an air-polluted city in Japan: a cross-sectional study. Int $J$ Chron Obstruct Pulmon Dis. 2019;14:791-798. doi:10.2147/COPD.S189372

9. de Miguel-díez J, Hernández-Vázquez J, López-de-Andrés A, Álvaro-Meca A, Hernández-Barrera V, Jiménez-García R. Analysis of environmental risk factors for chronic obstructive pulmonary disease exacerbation: a case-crossover study (2004-2013). PLoS One. 2019;14(5):e0217143. doi:10.1371/journal.pone.0217143

10. Yan $P$, Liu $P$, Lin R, et al. Effect of ambient air quality on exacerbation of COPD in patients and its potential mechanism. Int J Chron Obstruct Pulmon Dis. 2019;14:1517-1526. doi:10.2147/COPD.S190600

11. Brimkulov NN, Vinnikov DV, Davletalieva NE, Nyholm J, Uchkempirova B, Erhola M. Guidelines on Spirometry for Medicals of Kyrgyzstan. Kyrgyz-Finnish Lung Health Programme. Bishkek, 2005.

12. Miller MR, Hankinson J, Brusasco V et al. Standardisation of spirometry. Eur Respir J. 2005;26(2):319-338. doi:10.1183/090319 36.05.00034805

13. Singh D, Agusti A, Anzueto A, et al. Global strategy for the diagnosis, management, and prevention of chronic obstructive lung disease: the GOLD science committee report 2019. Eur Respir J. 2019;53:5. doi:10.1183/13993003.00164-2019

14. Meteran H, Miller MR, Thomsen SF, Christensen K, Sigsgaard T, Backer V. The impact of different spirometric definitions on the prevalence of airway obstruction and their association with respiratory symptoms. ERJ Open Res. 2017;3:4. doi:10.1183/23120541.00110-2017

15. Liu S, Zhou Y, Liu S, et al. Clinical impact of the lower limit of normal of FEV1/FVC on detecting chronic obstructive pulmonary disease: a follow-up study based on cross-sectional data. Respir Med. 2018;139:27-33. doi:10.1016/j.rmed.2018.04.011

16. Karrasch S, Brüske I, Smith MP, et al. What is the impact of different spirometric criteria on the prevalence of spirometrically defined COPD and its comorbidities? Results from the population-based KORA study. Int J Chron Obstruct Pulmon Dis. 2016; 11:1881-1894. doi:10.2147/COPD.S104529

17. Sator L, Horner A, Studnicka M, et al. Overdiagnosis of COPD in subjects with unobstructed spirometry: a BOLD analysis. Chest. 2019;156(2):277-288. doi:10.1016/j.chest.2019.01.015

18. Torén K, Andersson M, Olin A-C, Blanc PD, Järvholm B. Airflow limitation classified with the fixed ratio or the lower limit of normal and cause-specific mortality - A prospective study. Respir Med. 2018; 144:36-41. doi:10.1016/j.rmed.2018.10.001
19. Borlée F, Yzermans CJ, Krop E, et al. Spirometry, questionnaire and electronic medical record based COPD in a population survey: comparing prevalence, level of agreement and associations with potential risk factors. PLoS One. 2017;12(3):e0171494. doi:10.1371/journal. pone.0171494

20. Hansell A, Ghosh RE, Poole S, et al. Occupational risk factors for chronic respiratory disease in a New Zealand population using lifetime occupational history. J Occup Environ Med. 2014;56 (3):270-280. doi:10.1097/01.jom.0000438382.33221.dc

21. Torén K, Vikgren J, Olin A-C, Rosengren A, Bergström G, Brandberg J. Occupational exposure to vapor, gas, dust, or fumes and chronic airflow limitation, COPD, and emphysema: the Swedish CArdioPulmonary BioImage Study (SCAPIS pilot). Int J Chron Obstruct Pulmon Dis. 2017;12:3407-3413. doi:10.2147/COPD.S1 44933

22. Ryu JY, Sunwoo YE, Lee S-Y, et al. Chronic obstructive pulmonary disease (COPD) and vapors, gases, dusts, or fumes (VGDF): a meta-analysis. COPD J Chronic Obstr Pulm Dis. 2015;12 (4):374-380. doi:10.3109/15412555.2014.949000

23. Vinnikov D, Semizhon S, Rybina T, Savich L, Scherbitsky V, Manichev I. Occupation and chronic obstructive pulmonary disease in Minsk tractor plant workers. Am J Ind Med. 2017;60 (12):1049-1055. doi:10.1002/ajim.22776

24. Hasunuma H, Yamazaki S, Tamura K, et al. Association between daily ambient air pollution and respiratory symptoms in children with asthma and healthy children in western Japan. J Asthma off J Assoc Care Asthma. 2018;55(7):712-719. doi:10.1080/02770903.2017.136 9988

25. Knibbs LD, Cortés de Waterman AM, Toelle BG, et al. The Australian Child Health and Air Pollution Study (ACHAPS): a national population-based cross-sectional study of long-term exposure to outdoor air pollution, asthma, and lung function. Environ Int. 2018;120:394-403. doi:10.1016/j.envint.2018.08. 025

26. Cilluffo G, Ferrante G, Fasola S, et al. Associations of greenness, greyness and air pollution exposure with children's health: a crosssectional study in Southern Italy. Environ Health Glob Access Sci Source. 2018;17(1):86. doi:10.1186/s12940-018-0430-x

27. Skrzypek M, Kowalska M, Kasznia-Kocot J, Czech EM, Niewiadomska E. Respiratory health problems in adolescents living near main roads in the Upper Silesian industrial zone, Poland. Int J Occup Med Environ Health. 2019;32(4):553-567. doi:10. 13075/ijomeh.1896.01342 
Video abstract

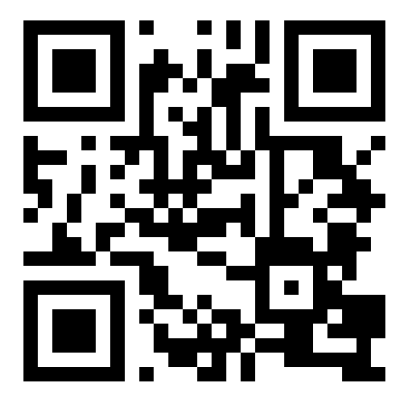

Point your SmartPhone at the code above. If you have a QR code reader the video abstract will appear. Or use: https://youtu.be/Boy6SXK9EzE

\section{Publish your work in this journal}

The International Journal of COPD is an international, peer-reviewed journal of therapeutics and pharmacology focusing on concise rapid reporting of clinical studies and reviews in COPD. Special focus is given to the pathophysiological processes underlying the disease, intervention programs, patient focused education, and self management protocols. This journal is indexed on PubMed Central, MedLine and CAS. The manuscript management system is completely online and includes a very quick and fair peer-review system, which is all easy to use. Visit http://www.dovepress.com/testimonials.php to read real quotes from published authors. 